\section{RUMAH BELAJAR "TORE AJHER" SEBAGAI UPAYA MEMBANGUN BUDAYA LITERASI DAN GEMAR BELAJAR SAINS SISWA DI SEKOLAH - SEKOLAH DESA ANDULANG KECAMATAN GAPURA}

\author{
Herowati', Lutfiana Fazad Azizah² \\ ${ }^{1,2)}$ Fakultas Keguruan dan IImu \\ Pendidikan, Universitas Wiraraja \\ * Herowati \\ Email : herowati.fkip@wiraraja.ac.id
}

\begin{abstract}
The daily life of the people in Andulang Village is closely related to science. This condition becomes a potential that can be developed to introduce the learning age community to play activities by utilizing simple science learning media around the environment. It does not only focus on references provided by the school. This service activity aims to facilitate reading access (availability of a reading place or books), enable a place to play and learn science in a fun way with simple experiments using used items in the surrounding environment to increase enthusiasm for learning science. The results of the implementation of community service activities take place by facilitating a reading area (Tore Ajher's House) and reading books containing some material at the elementary school level, and facilitating a place for students to play while learning in the surrounding environment through simple experiments such as plant grouping, air pressure and several experimental activities other simple by taking advantage of the surrounding environment. In literacy activities, students seem to enjoy reading and are active during the implementation of activities.

Keyword: Study house, Literacy, Likes to study sains
\end{abstract}

\begin{abstract}
Abstrak
Kehidupan sehari-hari masyarakat di Desa Andulang sangat erat kaitannya dengan Sains. Kondisi ini menjadi suatu potensi yang dapat di kembangkan untuk mengenalkan masyarakat usia usia belajar pada kegiatan bermain dengan memanfaatkan media pembelajaran Sains sederhana disekitar lingkungan supaya tidak hanya fokus pada referensi yang diberikan sekolah. Kegiatan pengabdian ini bertujuan untuk memfasilitasi akses baca (ketersediaan tempat baca atau buku), memfasilitasi tempat untuk bermain dan belajar sains yang menyenangkan dengan percobaan sederhana menggunakan barang bekas di lingkungan sekitar untuk meningkatkan gemar belajar sains. Hasil pelaksanaan kegiatan pengabdian berlangsung dengan memfasilitasi tempat baca (Rumah Tore Ajher) dan buku bacaan yang berisi beberapa materi pada jenjang Sekolah Dasar serta memfasilitasi tempat bagi siswa untuk bermain sambil belajar di lingkungan sekitar melalui perobaan sederhana seperti pengelompokan tumbuhan, tekanan udara dan beberapa kegiatan percobaan sederhana lainnya dengan memanfatkan lingkungan sekitar. Pada kegiatan literasi siswa terlihat senang membaca dan aktif saat pelaksanaan kegiatan.

Kata Kunci: Rumah belajar, Literasi, Gemar belajar sains
\end{abstract}


RUMAH BELAJAR “TORE AJHER” SEBAGAI UPAYA MEMBANGUN BUDAYA LITERASI DAN GEMAR BELAJAR SAINS SISWA DI SEKOLAH - SEKOLAH DESA ANDULANG KECAMATAN GAPURA

Herowati, Lutfiana Fazad Azizah

Volume 1, No. 1, April 2021 hal. 44-50

DOI Artikel : 10.46306/jub.v1i1.8

\section{PENDAHULUAN}

Desa Andulang merupakan salah satu Desa yang ada di Kecamatan Gapura Kabupaten Sumenep. Desa Andulang memiliki 5 Dusun yang terdiri dari Dusun Darma Ayu, Gunong, Pakamben, Laok Lorong dan Cem Manis. Tim PKM Prodi Pendidikan IPA Universitas Wiraraja melakukan observasi awal ke lima dusun yang ada di Desa Andulang. Hasil Observasi dari segi sumber daya alam (SDA), Desa Andulang memiliki potensi pohon kelapa, pohon jati dan pohon pisang. Masyarakat memanfaatkan SDA misalnya batok dan sabut pohon kelapa untuk bahan bakar memasak yang disebut dengan "kompor tomang", pohon pisang dimanfaatkan untuk konsumsi kebutuhan rumah tangga. Dari segi mata pencaharian, masyarakat Desa Andulang bekerja sebagai petani musiman dan sebagai pekerja dalam pembuatan genting rumah. Observasi awal juga dilakukan untuk mengetahui kehidupan sehari-hari anak di Desa Andulang. Desa Andulang memiliki masyarakat usia belajar 7 sampai 12 tahun yang sangat produktif yang harus bisa memanfaatkan waktu bermain dan belajar dengan sebaik-baiknya agar dapat membawa perubahan pada dirinya, keluarganya, dan pada lingkungannya. Anak-anak di Desa Andulang malakukan aktivitas disekitar lingkungan rumahnya. Setiap hari mereka bermain, melihat kegiatan memasak menggunakan kompor tomang, dan sering ikut ke tempat pembuatan genting yang sebagian besar merupakan mata pencaharian masyarakat Desa Andulang.

Masyarakat Desa Andulang sebagian besar melakukan kegiatan sehari-hari erat kaitannya dengan pembelajaran IPA/ sains, misalnya pada kegiatan memanfaatkan batok dan sabut pohon kelapa untuk bahan bakar memasak, dan pada proses pembuatan genting rumah merupakan salah satu media untuk materi pembelajaran IPA yaitu materi perubahan fisika dan kimia benda. Hasil wawancara yang dilakukan terhadap siswa yang tinggal di Desa Andulang mendapatkan hasil bahwa mereka hanya fokus belajar dengan menggunakan referensi yang di dapatkan dari sekolah. Anak-anak di Desa Andulang merasa lebih senang jika mereka bisa belajar di alam dan membuktikan apa yang dipelajari di lingkungannya, namun hal tersebut tidak dapat dilakukan karena kesulitan untuk mencari literatur baca yang sesuai. Kurangnya media pembelajaran serta tidak adanya buku untuk menambah pengetahuan anak menjadi penyebab belajar di rumah menjadi tidak menyenangkan karena rasa ingin tahu anak terhambat. Akibatnya anakanak lebih memilih sekedar berkumpul dan bermain tanpa adanya aktivitas bermain dan belajar.

Kegiatan masyarakat dengan kegiatan bermain bersama di lingkungan sekitar merupakan potensi yang dapat dikembangkan untuk lebih mengenalkan senangnya bermain sambil belajar sains dengan memanfaatkan media pembelajaran sains sederhana yang banyak ditemukan dilingkungan sekitar siswa (Putra, 2013) misalnya bermain sa'massa'an (masak-masakan) menggunakan bahan kayu, bambu, daun di lingkungan sekitar. Adanya beberapa kegiatan bermain siswa yang tidak bermanfaat harus ditanggulangi bersama agar masyarakat usia belajar 7 sampai 12 tahun bisa memanfatkan waktu luang mereka dengan kegiatan bermain dan belajar yang bermanfaat untuk masa depan. Perlu adanya kegiatan yang lebih memotivasi siswa-siswi di Desa Andulang dalam mengenal sains. Penguatan kegiatan ini dapat dilakukan dengan pendidikan non formal seperti rumah belajar. Rumah belajar memiliki peran penting serta berpengaruh aktif dalam mengubah softskill anak-anak sekolah dasar dan sebagai sarana informasi dan pusat belajar di lingkungan sekitar. Rumah belajar memiliki peran aktif jika dikembangkan sesuai dengan kebutuhan anak. Ketertarikan terhadap rumah belajar akan menarik keinginan anak untuk membaca 
RUMAH BELAJAR “TORE AJHER” SEBAGAI UPAYA MEMBANGUN BUDAYA LITERASI DAN GEMAR BELAJAR SAINS SISWA DI SEKOLAH - SEKOLAH DESA ANDULANG KECAMATAN GAPURA

Herowati, Lutfiana Fazad Azizah

Volume 1, No. 1, April 2021 hal. 44-50

DOI Artikel : 10.46306/jub.v1i1.8

(Abidin and Yunansah, 2018). Rumah belajar juga berperan untuk menyediakan buku bacaan yang dapat dimanfaatkan oleh siswa untuk belajar.

Berdasarkan uraian diatas, maka diperlukan rumah belajar "Tore Ajher" sebagai sarana membangun budaya literasi dan gemar belajar sains untuk anak-anak produkti (usia 7-12 tahun). Rumah belajar yang akan dikembangkan difokuskan pada, (I) memfasilitasi akses baca (ketersediaan tempat baca atau buku), (2) memfasilitasi tempat untuk bermain dan belajar sains yang menyenangkan dengan percobaan sederhana menggunakan barang bekas di lingkugan sekitar untuk meningkatkan gemar belajar sains siswa, (3) kegiatan literasi dan belajar sains yang menyenangkan tanpa biaya (gratis) dengan segala keramahan, serta keberlanjutan atau konsisten.

\section{METODE PENGABDIAN}

Tahapan pelaksanaan program

Tahapan pelaksanaan program pengabdian kepada masyarakat ini adalah sebagai berikut:

\section{a. Persiapan}

Sebelum dilakukan program pengabdian pada masyarakat, terlebih dahulu dilakukan survey lokasi, permasalahan, dan kebutuhan mitra. Mempersiapakan administrasi, koordinasi dengan mitra, penyusunan perangkat dan jadwal kegiatan program pengabdian kepada masyarakat.

\section{b. Penyelesaian masalah dan penyusunan solusi}

Tim pelaksana melakukan penyusunan solusi yang akan ditawarkan untuk menyelesaikan permasalahan mitra yaitu berupa sosialisasi, edukasi dan pendampingan kegiatan program pengabdian kepada masyarakat.

\section{c. Penyampaian solusi pada mitra}

Tim pelaksana PKM menyampaikan solusi yang ditawarkan kepada mitra yaitu melakukan pemberian bantuan berupa buku sebagai media literasi untuk kegiatan di rumah belajar "Tore Ajher" kemudian melakukan pendampingan edukasi dan belajar sains yang menyenangkan dengan memanfaatkan barang bekas di lingkungan sekitar sebagai alternative kegiatan edukasi yang efektif, interaktif dan inovatif untuk keberlanjutan kegiatan study house.

\section{d. Pendampingan}

Kegiatan pendampingan direncanakan akan dilaksanakan seminggu setelah kegiatan sosialisasi. Kegiatan pendampingan akan melibatkan masyarakat belajar membaca dan berimajinasi usia (7- 12 tahun) di Desa Andulang dengan tempat pelaksanaan di rumah salah satu warga yang bersedia dijadikan tempat rumah belajar "Tore Ajher".

\section{Pelaksanaan Kegiatan}

Metode pendekatan yang ditawarkan adalah edukasi materi literasi dan pendampingan kegiatan rumah belajar "Tore Ajher" bermain dan belajar sains yang menyenangkan dengan percobaan sederhana menggunakan barang bekas di lingkugan sekitar untuk meningkatkan gemar belajar sains siswa dan mewujudkan gerakan literasi siswa yang menyenangkan. Berdasarkan kebutuhan, beberapa hal yang dibutuhkan oleh siswa Masyarakat belajar membaca dan berimajinasi usia (7- 12 tahun) di Desa Andulang meliputi sarana dan prasarana yang perlu dipersiapkan pada kegiatan ini meliputi :

I. Buku literasi 
RUMAH BELAJAR “TORE AJHER” SEBAGAI UPAYA MEMBANGUN BUDAYA LITERASI DAN GEMAR BELAJAR SAINS SISWA DI SEKOLAH - SEKOLAH DESA ANDULANG KECAMATAN GAPURA

Herowati, Lutfiana Fazad Azizah

Volume 1, No. 1, April 2021 hal. 44-50

DOI Artikel : 10.46306/jub.v1i1.8

2. Berbagai media pembelajaran sains sederhana yang memanfaatkan barang bekas di lingkungan sekitar siswa

\section{Pelaksanaan Pelatihan}

Pada tahap ini mitra akan diajak dalam penyelenggaraan kegiatan yang dilakukan untuk beberapa tujuan, yaitu:

I. Kegiatan literasi yang menyenangkan untuk mewujudkan budaya literasi.

2. Kegiatan bermain dan belajar sains yang menyenangkan dengan percobaan sederhana menggunakan barang bekas di lingkugan sekitar sebagai upaya untuk meningkatkan gemar belajar sains siswa.

3. Kegiatan Pendampingan "Gerakan budaya literasi dan senang belajar sains" akan dilaksanakan rutin dan berkelanjutan.

\section{Pemantauan dan Refleksi}

Pada saat kegiatan berlangsung, setiap tahapan proses akan dilakukan pemantauan dan dicermati/dikendalikan, sesuai dengan rencana dan tujuan yang telah ditetapkan. Bila terjadi suatu keadaan yang di luar perhitungan, maka akan segera dilakukan langkah penyesuaian dan tindakan perbaikan. Setelah kegiatan dalam empat bulan, dilakukan refleksi untuk mengevaluasi apakah proses pada setiap tahapan kegiatan dan hasil telah sesuai dengan rencana. Kemudian tindak lanjut apa yang perlu dilakukan. Melalui refleksi/evaluasi ini, dosen yang bersangkutan, stake holder dan tim pengabdian melaksanakan pengelolaan kegiatan untuk keberlanjutan kegiatan.

\section{e. Pelaporan Akhir}

Laporan akhir merupakan laporan dari seluruh rangkaian kegiatan sebagai wujud pertanggung jawaban secara administratif dari tim pelaksana kepada LPPM

\section{PELAKSANAAN DAN PEMBAHASAN}

\section{Hasil Pelaksanaan Kegiatan}

Upaya pengembangan budaya literasi dan gemar belajar sains di Desa Andulang Kecamatan Gapura yang di wadahi oleh rumah Tore Ajher yang akan dilaksanakan dalam kegiatan pengabdian. Rumah Tore Ajher di rancang melalui kegiatan membaca buku bacaan atau komik yang bertema sains dengan beberapa level buku dari kelas I sampai 6 dan buku olimpiade. Buku bacaan tersebut berisi tentang ilmu-ilmu alam dan dilengkapi dengan percobaan-percobaan sederhana yang di desain menarik sehingga siswa lebih tertarik untuk membaca dan belajar serta memahami isi dari buku tersebut. Siswa yang ikuti dalam kegiatan ini terdiri dari kelas I sampai 6 Sekolah Dasar di Desa Andulang Kecamatan Gapura. Kegiatan ini berlangsung selama 2 Minggu setiap hari sabtu dan minggu pada tanggal 29 \& 30 Agustus hingga 5 \& 6 September 2020. Kegiatan literasi sains di rumah belajar "Tore Ajher" akan ditetapkan setiap hari minggu pagi dengan bantuan dari masyarakat yang ikut serta membimbing selama kegiatan PKM dengan pantauan, evaluasi dan refleksi kegiatan yang berkesinambungan dari tim PKM prodi Pendidikan IPA Universitas Wiraraja.

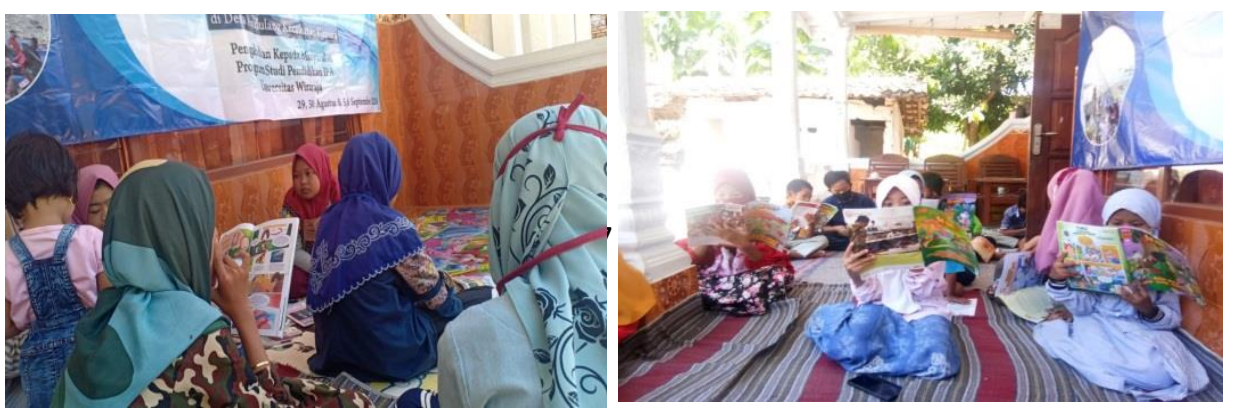


RUMAH BELAJAR “TORE AJHER” SEBAGAI UPAYA MEMBANGUN BUDAYA LITERASI DAN GEMAR BELAJAR SAINS SISWA DI SEKOLAH - SEKOLAH DESA ANDULANG KECAMATAN GAPURA

Herowati, Lutfiana Fazad Azizah

Volume 1, No. 1, April 2021 hal. 44-50

DOI Artikel : 10.46306/jub.v1i1.8

Gambar 3.1 Literasi \& Edukasi Sains Siswa Di Desa Andulang Kecamatan Gapura.

Pada hari pertama sampai hari terakhir, siswa melakukan kegiatan dengan membaca bersama dengan buku literatur berupa buku teks dan komik dengan tema sains. Setelah siswa sudah dapat memahami isi buku, siswa melakukan refleksi dengan menceritakan kembali isi buku pada siswa lain. Saat proses tersebut siswa tidak lepas dalam bimbingan tutor, dimana tutor akan siaga dalam membantu siswa saat kegiatan berlangsung. Pada akhir kegiatan tutor memberikan penguatan kepada siswa lainnya sesuai dengan yang sudah dijelaskan tadi.
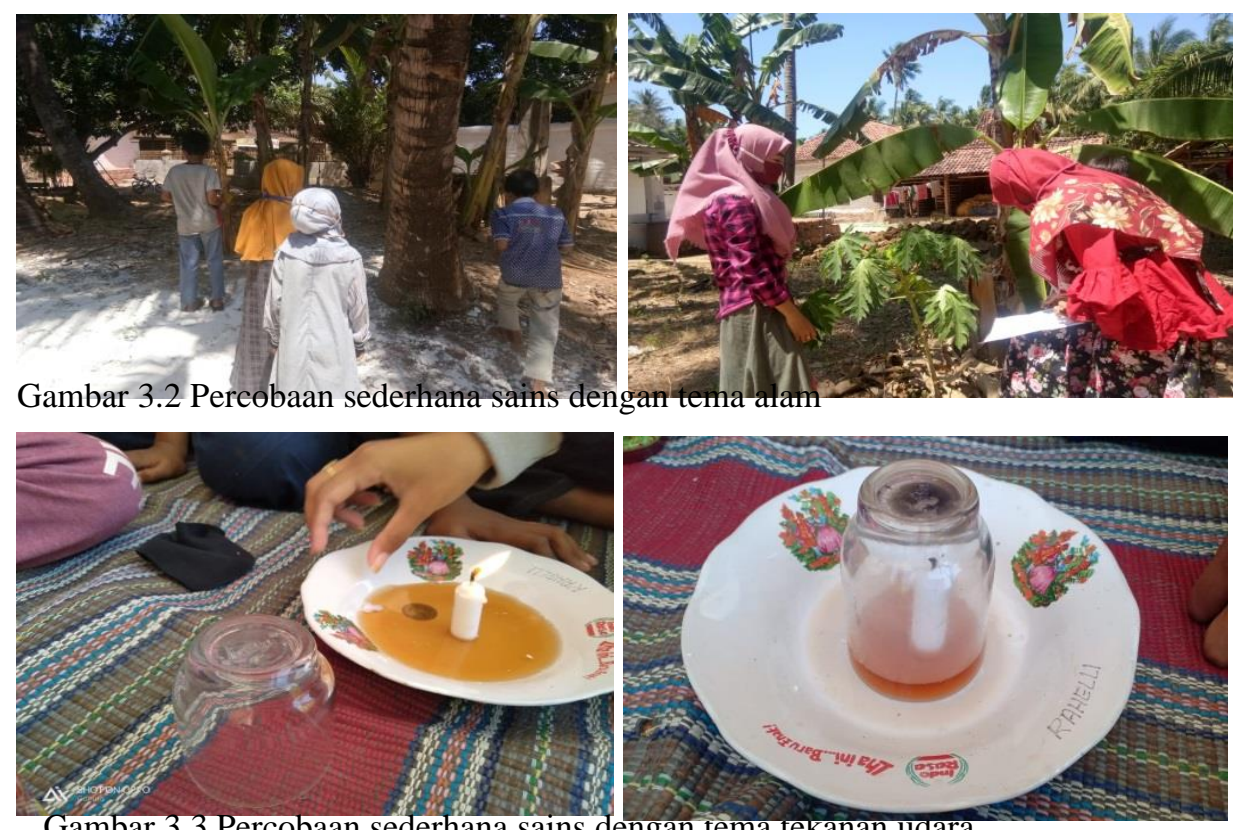

Pada kegiatan ini diakhiri terdapat suatu percobaan sederhana yang digunakan sebagai kegiatan tambahan agar menambah wawasan siswa. Kegiatan di rancang dalam bentuk eksperimen yang bersifat kontekstual. Kegiatan ekperimen pertama dilakasanakan dengan tema belajar alam. Siswa secara langsung belajar dengan alam di lingkungan sekitar mengenai macam-macam tumbuhan monokotil dan dikotil beserta contohnya gambar 3.2. Kegiatan ekperimen kedua dilaksanakan dengan tema tekanan udara yaitu percobaan mengenai tekanan udara yang lebih besar yang disebabkan adanya api dalam suatu ruangan tersebut sehingga udara yang diluar ruangan akan masuk ke dalam ruangan yang memiliki tekanan udara lebih tinggi yang dibuktikan dengan padamnya api dalam ruangan tersebut (gambar 3.5 dan gambar 3.6).

\section{Pembahasan Hasil Pelaksanaan Kegiatan}

Pada pengabdian masyarakat di Desa Andulang Kecamatan Gapura selama 4 pertemuan siswa terlihat sangat antusias. Dalam pelaksanaan pengabdian, siswa yang hadir di rumah "Tore Ajher" terdiri dari perwakilan kelas Sekolah dasar mulai dari kelas I sampai kelas 6. Rumah "Tore Ajher” yang dikembangkan fokus pada beberapa hal yang terlaksana secara keseluruhan dalam proses pelaksanaan kegiatan. Rumah “Tore Ajher” fokus pada memfasilitasi akses baca (ketersediaan tempat baca dan buku), hal tersebut sudah terlaksana dan tercapai dengan menyediakan buku bacaan yang berisi tentang beberapa materi pada jenjang Sekolah Dasar sehingga saat proses kegiatan siswa sudah dapat menerima dengan baik materi atau bacaan yang dibaca selama kegiatan berlangsung. Siswa yang kurang memahami bacaan akan bertanya 
RUMAH BELAJAR “TORE AJHER" SEBAGAI UPAYA MEMBANGUN BUDAYA LITERASI DAN GEMAR BELAJAR SAINS SISWA DI SEKOLAH - SEKOLAH DESA ANDULANG KECAMATAN GAPURA

Herowati, Lutfiana Fazad Azizah

Volume 1, No. 1, April 2021 hal. 44-50

DOI Artikel : 10.46306/jub.v1i1.8

langsung terhadap tutor hingga siswa dapat memahami bacaan yang dibaca. Ketersediaan bahan bacaan untuk siswa akan membuat pelajaran menjadilebih efektif dan efisien (Saefuddin dan Berdiati, 20I4).

Rumah “Tore Ajher” juga fokus pada solusi untuk memfasilitasi tempat bermain dan belajar sains yang menyenangkan bagi siswa. Pada kegiatan ini siswa diajak bermain sambil bereksperimen atau melakukan perocobaan sederhana di lingkungan sekitar untuk membuktikan teori yang telah mereka baca dan pahami pada buku bacaan yang telah disediakan. Siswa diarahkan untuk melakukan percobaan sederhana sebanyak dua kali. Percobaan pertama siswa diajak untuk bermain di lingkungan sekitar sambil mengamati berbagai macam tumbuhan lalu mengelompokkannya. Percobaan kedua dilakukan dengan mengajak siswa untuk bermain sambil belajar tentang tekanan udara menggunakan lilin dan gelas. Keberhasilan kegiatan ini dapat dilihat pada keaktifan siswa. Keaktifan siswa dalam kegiatan ini mengalami peningkatan dimana siswa yang awal pertemuan hanya mengikuti kegiatan dengan kurang aktif dan perlu bimbingan dari tutor namun pada minggu selanjutnya siswa cepat dapat berinteraksi dengan lingkungannya yang baru. Pembelajaran kontekstual yang dikaitkan dengan pembelajaran IPA mampu menarik minat untuk belajar sehingga hasil belajar meningkat dan lebih bermakna bagi siswa (Fahmiari, 2014). Pada kegiatan ini siswa diharapkan dapat gemar membaca dan dapat menambahkan wawasan dalam hal sains. Proses pelaksanaan percobaan sederhana dengan memanfaatkan lingkungan sekitar yang mengarahkan siswa untuk bermain sambil belajar mampu meningkatkan pemahaman siswa tentang sains (Trianto, 2013) terutama hubungan antara konsep sains yang dipelajari disekolah dengan lingkungan tempat tinggal mereka (Rusman, 20I7). Kegiatan ini akan dibuat secara berkelanjutan dengan tetap meningkatkan minat baca siswa di Desa Andulang Kecamatan Gapura.

\section{KESIMPULAN DAN SARAN}

Budaya literasi dan gemar belajar sains dapat dibangun melalui pendidikan non formal rumah belajar "Tore Ajher" yang dilaksanakan dalam kegiatan pengabdian. Rumah Tore Ajher memfasilitasi akses baca bagi siswa (berupa buku bacaan dan tempat belajar) dan memfasilitasi tempat belajar sains yang menyenangkan melaui kegiatan bermain sambil belajar tanpa biaya atau gratis. Kegiatan ini dilakukan sebanyak 4 kali pertemuan. Pertemuan pertama dan kedua dilaksanakan dengan agenda kegiatan membaca bersama menggunakan buku bacaan yang telah disediakan. Pertemuan ketiga dan keempat dilaksanakan dengan agenda kegiatan belajar sambil bermain melalui percoban sederhana dilingkungan sekitar siswa. Siswa terlihat aktif dan antusias (untuk membaca dan melakukan percobaan) saat pelaksanaan program pengabdian. 
RUMAH BELAJAR “TORE AJHER” SEBAGAI UPAYA MEMBANGUN BUDAYA LITERASI DAN GEMAR BELAJAR SAINS SISWA DI SEKOLAH - SEKOLAH DESA ANDULANG KECAMATAN GAPURA

Herowati, Lutfiana Fazad Azizah

Volume 1, No. 1, April 2021 hal. 44-50

DOI Artikel : 10.46306/jub.v1i1.8

\section{DAFTAR PUSTAKA}

Abidin, Y. Mulyani, T. Yunansah. (2018). PEMBELAJARAN LITERASI: Strategi Meningkatkan Kemampuan Literasi Matematika, Sains, Membaca, dan Menulis. Jakarta:Bumi Aksara.

Fahmiati (2014) 'Peningkatan Hasil Belajar IPA Terpadu Melalui Model Pembelajaran KontekstuaL', Jurnal Nalar Pendidikan, 2(2), pp. 85-89. Available at: http://ojs.unm.ac.id/nalar/article/view/l973.

Fatimah, S., \& Ulum, M. S. (2018). Learning Methods for Children with Autism in Rumah Belajar Inklusi MB3. Proceedings of the Ist International Conference on Recent Innovations. doi: $10.5220 / 00099 \mid 6707730779$

Penerapan Model Pembelajaran Inovatif Yang Memanfaatkan Rumah Belajar Di Sekolah Model Pustekkom Jenjang SMP DI BOGOR. (n.d.). doi:10.32550/teknodik.v0i0.367.s83

Putra, Sitiatava R. (20I3). Desain Belajar Mengajar Kreatif Berbasis Sains. Jogjakarta: DIVA Press.

Rusman (2017) Belajar dan Pembelajaran Berorientasi Standar Proses Pendidikan. Jakarta: PT Kharisma Putra Utama.

Saefuddin, A. and Berdiati, I. (2014) Pembelajaran Efektif. Bandung: PT Remaja Rosdakarya Offset. Trianto. (2013). Model Pembelajaran Terpadu. Jakarta: Bumi Aksara. 